\title{
SPATIAL VARIATION OF GROUND MOTION DETERMINED FROM ACCELEROGRAMS RECORDED ON A HIGHWAY BRIDGE
}

\author{
By John C. Wilson* and PaUl C. Jennings
}

\begin{abstract}
A set of time-synchronized strong-motion accelerograms, obtained on the San Juan Bautista 156/101 Separation Bridge in California during the 6 August 1979 Coyote Lake earthquake $\left(M_{L}=5.9\right)$, are used to study the spatial variation of ground motion at the bridge site, including traveling wave effects and the influence of multiple-support excitation. Analysis of the ground motion recorded at the base of two of the bridge supports $(32.6 \mathrm{~m}$ apart) revealed the presence of a differential support excitation having a period of $\approx 3 \mathrm{sec}$, much longer than any structural periods of the bridge. This signal also appeared as a noticeable long-period component in the superstructure displacements. Analysis of the vertical and radial components of the 3-sec ground motion indicated that ground displacements were retrograde for the duration of strong shaking, with several cycles exhibiting elliptical particle motions. These findings suggest that longperiod differential support motions were induced by phase delays in a Rayleigh wave traveling across the bridge site. Further support to this premise is given by the location of the bridge site near a maxima of the Rayleigh wave radiation pattern for the Coyote Lake earthquake (based on published focal mechanism data). Traveling wave effects were also detected for compressional body waves by a correlation analysis which indicated a time delay of $\approx 7 \mathrm{msec}$ between $P$. wave arrivals at two of the bridge supports.
\end{abstract}

\section{INTRODUCTION}

In dynamic analysis for earthquake engineering, it is common to assume that the entire base of a structure is uniformly subjected to the same ground motion. That is, the amplitude and phase characteristics of the ground motion are identical at all points where the structure is attached to the ground. This assumes that the ground motion is a result of spatially uniform, vertically propagating shear waves, or, that the wavelengths of the ground motions are long with respect to the dimensions of the structure. The assumption of uniform ground motion has usually been adopted for several reasons: (1) the scarcity of observed data on the spatial variations of seismic ground motions over distances comparable to the base dimensions of most structures; (2) the expediency of solving equations of motion for uniform base excitation (as opposed to equations for differential excitations); and (3) physical reasoning that indicates such an assumption will be very nearly satisfied for many common engineering structures. However, for structures of large spatial extent, such as bridges and pipelines, variation in ground motion over the length of support of the structure may be great enough to make the assumption of uniform ground motion inappropriate. In this case, the different ground motions occurring at each support create what is often referred to as the problem of "multiple-support excitation."

The measurement and analysis of differential seismic ground motions occurring over distances of several tens to several hundreds of meters is of significant interest to both seismologists and earthquake engineers, and in particular, to bridge engi-

* Present address: Department of Civil Engineering and Engineering Mechanics, McMaster University, Hamilton, Ontario, Canada L8S 4L7. 
neers. One of the earliest studies of the effects of traveling seismic waves on bridge structures was conducted by Bogdanoff et al. (1965) who examined the case of a seismic motion propagating along the length of a bridge foundation. The bridge responses were found to be noticeably different from those due to a uniform, rigid base excitation. Werner et al. (1977) and Werner and Lee (1980), investigating the effects of traveling seismic waves on the response of a single-span bridge, report that both the type of seismic wave as well as the angle of approach may substantially influence a bridge's dynamic response. Abdel-Ghaffar (1977) has also studied the problem and reports similar results. More recently, Smith et al. (1982) have examined some of the seismological aspects of the spatial variations of seismic ground motions using closely spaced array data for the 1979 Imperial Valley earthquake.

Although many modern buildings are instrumented with strong-motion accelerographs, and many excellent records have been obtained from these installations, it was not until the mid-1970's that a program of strong-motion instrumentation of bridges and other transportation structures was initiated in California. The first set of accelerograms was obtained from this program when the San Juan Bautista 156/ 101 Separation Bridge was shaken by the 6 August 1979 Coyote Lake, California, earthquake. In this paper, records of the ground motion at the San Juan Bautista bridge site (provided by the California Division of Mines and Geology) are used to examine the nature of the seismic excitation to which the bridge was subjected during the 1979 Coyote Lake earthquake. It must be mentioned that, with the limited amount of data available, simplifying assumptions and approximate analyses were needed in order to assess the contribution of differential support motions. In an attempt to offset some of these limitations, several different lines of evidence are used in support of the various observations and conclusions.

\section{The San Juan BaUtista Bridge}

The purpose of this and the following section is to provide a general description of the San Juan Bautista 156/101 Separation Bridge and a discussion of the strongmotion instrumentation system deployed on the bridge. The availability of strong ground motion records at two separate stations at the bridge site provides the basis for subsequent analyses in this paper.

The San Juan Bautista 156/101 Separation Bridge is located approximately $3 \mathrm{~km}$ northwest of the town of San Juan Bautista in San Benito County, California (see Figure 1). This two-lane, six-span bridge, constructed in 1959 and owned by the California Department of Transportation (Caltrans), carries a moderate amount of automobile and truck traffic on California State Highway 156 over U.S. Highway 101 , and is typical of the late 1950's, early 1960's style of highway bridge design in the United States. Views of the bridge and typical dimensions are shown in Figure 2. Since this paper is concerned with an examination of the characteristics of the ground motions at the bridge site, only those structural features which directly pertain to the foundation substructure will be discussed here.

Foundation support for the bridge consists of spread footings bearing directly on horizontal beds of Pliocene alluvial deposits estimated to be approximately $15 \mathrm{~m}$ in thickness, which in turn overlie granitic basement rock (Porter et al., 1983). Soil tests at the bridge site prior to construction gave Standard Penetration Test values of $N$ of approximately 50 . Values of $N$ this high are indicative of a very dense soil (Scott, 1981). 
The left abutment, denoted as A1 on Figure 2, was constructed on a naturally occurring rise of the ground surface while the right abutment (A7 on Figure 2) was constructed on fill material. The abutments and bents are skewed at $34.8^{\circ}$ with respect to the bridge deck. For later discussions, a global $X-Y-Z$ coordinate system is defined such that the $X$ axis points in the longitudinal direction (parallel to the

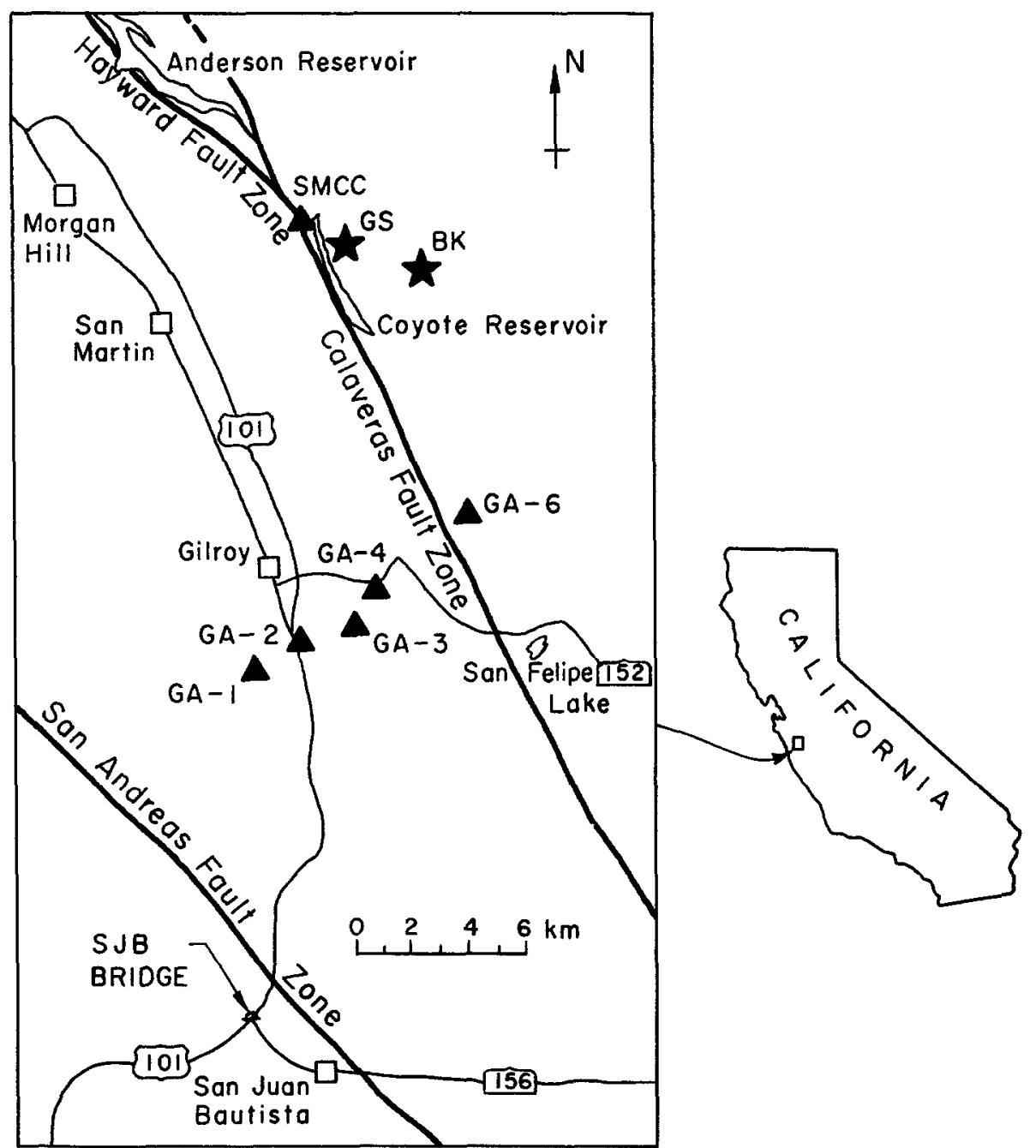

FIG. 1. Location of the San Juan Bautista 156/101 Separation Bridge and epicenter of the 1979 Coyote Lake earthquake. The solid triangles locate strong-motion accelerograph stations in addition to those at the bridge and in the town of San Juan Bautista. The epicenter locations determined by the U.S. Geological Survey (GS) and the University of California at Berkeley (BK) are indicated with stars (after Liu and Helmberger, 1983).

centerline of the road), the $Y$ axis points in a transverse direction, and the $Z$ axis is vertical. The bearing of the positive $X$ axis shown in Figure 2 is $\mathbf{S} 58^{\circ} \mathrm{E}$.

\section{STRONG-Motion INSTRUMENTATION}

In 1977, the.San Juan Bautista bridge was instrumented by the Office of Strong Motion Studies of the California Division of Mines and Geology with 12 channels 
of strong-motion instrumentation, all linked to a central recording system having a common trigger and time signal. The strong-motion transducers were force balance accelerometers (Kinemetrics FBA-1 and FBA-3 models) which were connected to a CRA-1 central recording system. Six transducers were placed at ground level to measure input motions at the foundation, three at bent 3 (denoted as B3 on Figure 2 ) and three at bent 5 (B5). The remaining six transducers were placed at various locations on the bridge superstructure. The orientation of each transducer is indicated by the arrows in Figure 2.

The main shock of the 6 August 1979 Coyote Lake earthquake $\left(M_{L}=5.9\right)$ triggered the system and resulted in the recording of approximately $27 \mathrm{sec}$ of acceleration on each of the 12 channels. The peak recorded ground acceleration
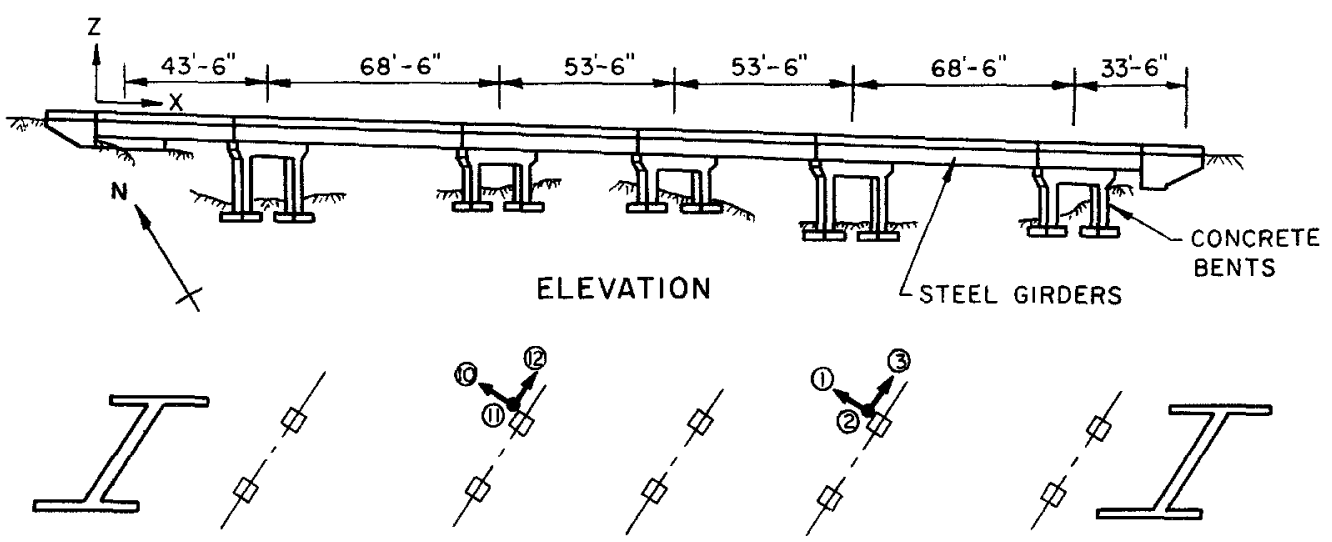

FOUNDATION PLAN

(6) 4,5 mounted on top of bent 5

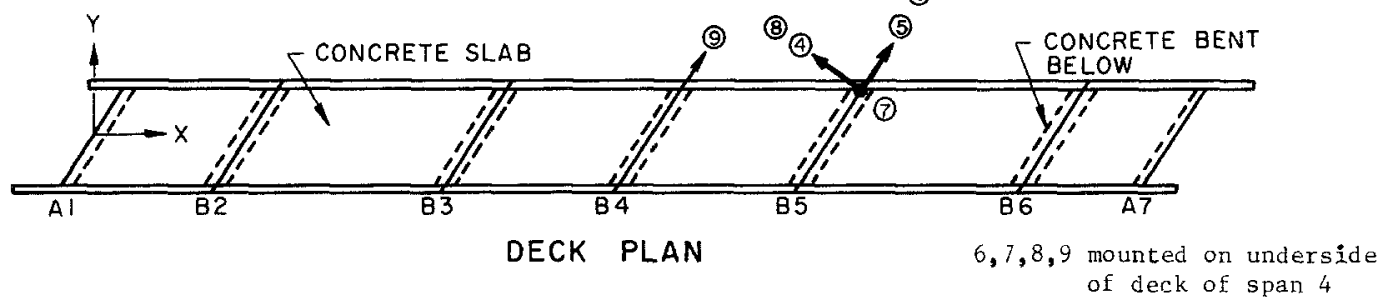

Fig. 2. Details of the foundation, superstructure, and strong-motion instrumentation of the San Juan Bautista 156/101 Separation Bridge. Arrows indicate the orientation of each numbered transducer (after Porcella et al., 1979).

(channel 1 on Figure 2) was $0.12 \mathrm{~g}$, and the peak recorded structural response (on channel 8) was $0.27 \mathrm{~g}$ (corrected absolute values) with the duration of strong motion lasting about 10 seconds.

The instrumentation system was designed to measure the motion of a single bay and supporting bents. As a result, the lack of instruments at the abutments and at free-field locations was a limitation in determining a complete picture of the ground motions at the site. However, the two sets of ground level triaxial instruments did allow the ground motion to be studied at the base of bents 3 and 5 . Plots of corrected absolute accelerations for each ground motion data channel are shown in Figure 3.

In addition to the bridge site, several other strong motion accelerographs were deployed throughout the region. A linear array of five triaxial instruments spanned 

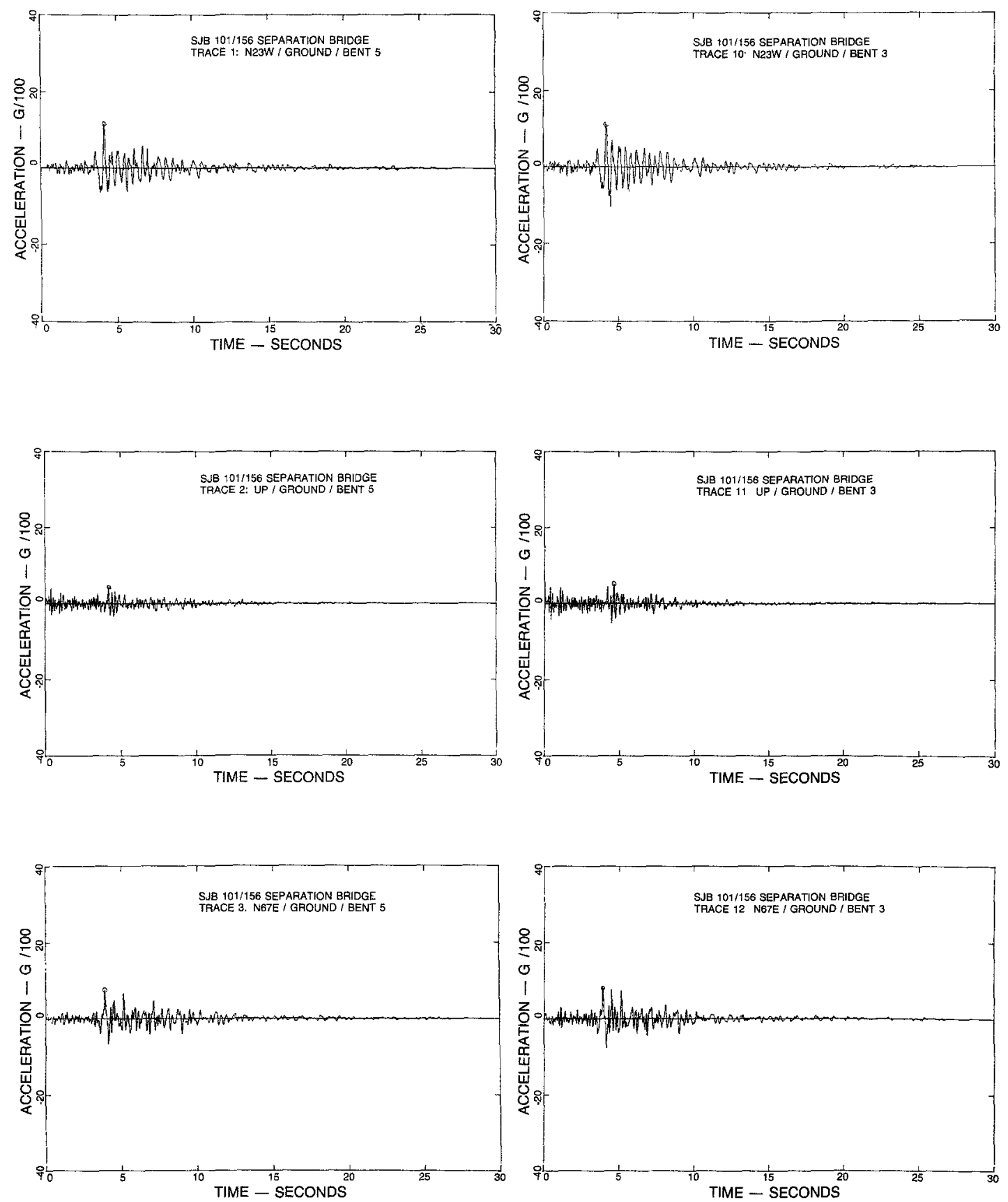

FIG. 3. Ground accelerations recorded at the foundations of the San Juan Bautista bridge during the 6 August 1979 Coyote Lake earthquake. The trace numbers correspond to the instrument locations on Figure 2.

the Calaveras fault zone in the vicinity of Gilroy, about $15 \mathrm{~km}$ north of the bridge. Also, there was an instrument installed in the town of San Juan Bautista, about 3 $\mathrm{km}$ southeast of the bridge. The locations of these instruments are also indicated on the map in Figure 1. With the availability of a significant number of near-source strong ground motion records and also world-wide teleseismic data, the Coyote Lake 
earthquake has been well researched (Uhrhammer, 1980; Joyner et al., 1981; Liu and Helmberger, 1983). Compilations of strong-motion records recovered from the earthquake are given by Porcella et al. (1979), and processed data from the San Juan Bautista bridge and the station in the town of San Juan Bautista are given by Porter et al. (1983). Liu and Helmberger (1983) report that the earthquake was nearly a pure strike-slip mechanism with strike $\left(\mathrm{N} 24^{\circ} \mathrm{W}\right)$ parallel to the Calaveras fault. They indicate that faulting initiated at a depth of $8 \mathrm{~km}$ and ruptured toward the southeast. The locations of the epicenter of the earthquake determined by the University of California, Berkeley (BK) and by the U.S. Geological Survey (GS) are also indicated on Figure 1 . They are about $3 \mathrm{~km}$ apart.

\section{Long-PERIOd ERrors in STrong-Motion Data}

In view of some of the analyses which follow, it is important that an examination be made of the possible errors present in the digitized accelerograms, and in the displacement time histories obtained by double integration of the accelerations. Since the accuracy of the data in this investigation is a concern only for lowfrequency signals, the following discussions will be restricted to the long-period components.

Typical accelerogram processing. The routine data processing of earthquake accelerograms as performed on the San Fernando data is described by Hudson (1979). Accelerograms typically written on $70-\mathrm{mm}$ film (by instruments with sensitivity of $1.9 \mathrm{~cm} / \mathrm{g}$, for the SMA-1 accelerograph) were photographically enlarged four times prior to digitization to give an effective sensitivity of $7.6 \mathrm{~cm} / \mathrm{g}$. The photographic enlargements were then digitized on a semi-automatic digitizing table which required that a human operator operator use a set of cross-hairs placed on the center of the trace to follow the accelerogram. Trifunac et al. (1973) report that of several possible errors, the human reading error was the main contributing factor to the variance of error in digitizing an accelerogram. For integrated displacement curves, the results of Trifunac et al. (1973) suggest that errors at periods of about $8 \mathrm{sec}$ may be near 1 $\mathrm{cm}$ when an effective sensitivity of $7.6 \mathrm{~cm} / \mathrm{g}$ is considered.

Hanks (1975) performed an empirical evaluation of the accuracy of ground displacement records using 234 components from the San Fernando earthquake and reports that, for an effective digitization sensitivity of $7.6 \mathrm{~cm} / \mathrm{g}$, displacement uncertainties are approximately 0.5 to $1 \mathrm{~cm}$ in the period range 5 to $8 \mathrm{sec}$, and 1 to $2 \mathrm{~cm}$ in the range 8 to $10 \mathrm{sec}$. Subsequent processing using a high-pass filter (with low-frequency corner $f_{L C}=0.125 \mathrm{~Hz}$ ) results in ground displacements which are considered to have a noise level of no more than $1 \mathrm{~cm}$ amplitude at a period of 8 sec. Both Trifunac et al. (1973) and Hanks (1975) indicate that this uncertainty decreases dramatically for shorter period components in the record. Basili and Brady (1979) have used the work of Hanks (1975) to establish an empirical criteria for the low frequency corner of a high-pass Ormsby filter and suggest that uncertainties in displacements may be $\pm 0.25 \mathrm{~cm}$ when $f_{L C}=0.25 \mathrm{~Hz}$.

Processing of the Coyote Lake earthquake data. The Coyote Lake data, processed by the California Division of Mines and Geology, were handled in a somewhat different manner than the San Fernando data. Details are provided by Porter et al. (1983), and similar processing used by Fletcher et al. (1980) for Oroville aftershocks provides additional insight into the techniques. The basic difference between the California Division of Mines and Geology procedures and the earlier San Fernando procedures is in the method of digitization. For the Coyote Lake event, the accelerograms were digitized from contact prints of the original film traces using a 
trace-following laser scan device. The original film traces for the San Juan Bautista bridge were recorded at a sensitivity of approximately $1.9 \mathrm{~cm} / \mathrm{g}$. The laser scanner's least count (ultimate resolution) is reported to be $1 \mu \mathrm{m}\left(10^{-6} \mathrm{~m}\right)$, and its random error in digitizing a straight line of similar photographic quality to the accelerogram traces is claimed to be $10 \mu \mathrm{m}$ (Porter et al., 1983).

The potential resolution of the laser scan device can be used to estimate the random noise level in the doubly integrated displacement signal. A random digitization error of $10 \mu \mathrm{m}$ on a trace with sensitivity of $1.9 \mathrm{~cm} / \mathrm{g}$ corresponds to $5.26 \times$ $10^{-4} \mathrm{~g}$. Hence, uncertainties in displacements for various periods are estimated to be $0.1 \mathrm{~mm}$ at $1 \mathrm{sec} 1 \mathrm{~mm}$ at $3 \mathrm{sec}$, and $8 \mathrm{~mm}$ at $8 \mathrm{sec}$. Since the Coyote Lake data was band-pass filtered with filter termination and corner frequencies $f_{L T}=0.05, f_{L C}$ $=0.25$ and $f_{H C}=23, f_{H T}=25 \mathrm{~Hz}$, the computed displacements may be expected to have an uncertainty of about $1 \mathrm{~mm}$ at periods of $3 \mathrm{sec}$.

In the next section, the uncertainties in computed displacements are used in an examination of differences in motions at the ground level stations at the San Juan Bautista bridge. The results will show that, while the differences in computed displacements at the two stations are of the same magnitude as the expected level of random digitization noise, several features of the data suggest that the differences are consistent with a differential motion of the supports caused by traveling wave effects.

\section{DifFERENTIAL SUPPORT MOTION}

Records taken at the base of bents 3 and 5 during the 1979 Coyote Lake earthquake provide a possibility to study the differences in ground motion occurring at two separate supports of the bridge. This marks one of the first instances where recorded strong ground motion and the associated structural responses might be used to examine the problem of multiple-support excitation of a bridge.

The $X, Y$, and $Z$ displacement components of ground motion at B3 and B5, obtained from double integration of the recorded ground accelerations, are shown in Figure 4, and appear to be well correlated for their respective directions. This correlation is to be expected because of the close proximity of the two stations. However, subtraction of the $X, Y$, and $Z$ pairs, as shown in Figure 5 , reveals what appears to be a differential displacement occurring between B3 and B5 with a period of about $3 \mathrm{sec}$. Superimposed on the early part of this signal are some small amplitude, higher frequency components but most of the differential amplitude is a result of the long-period component. If the doubly integrated accelerograms at the two locations had been identical in amplitude and phase, subtraction of the pairs of records would have yielded zero.

The presence of the 3-sec period component in the differential displacements may be partially explained as being a consequence of a phase delay in a long-period wave propagating across the bridge site. If one considers a sinusoidal wave traveling outward from the epicenter and across the bridge site with wave speed $c$ and frequency $\omega$, then for motions in the radial direction, the displacements at B3 and B5 are given by

$$
\begin{aligned}
& y_{3}(t)=A \cos \omega\left(t-\frac{x_{3}}{c}\right) \\
& y_{5}(t)=A \cos \omega\left(t-\frac{x_{5}}{c}\right) .
\end{aligned}
$$



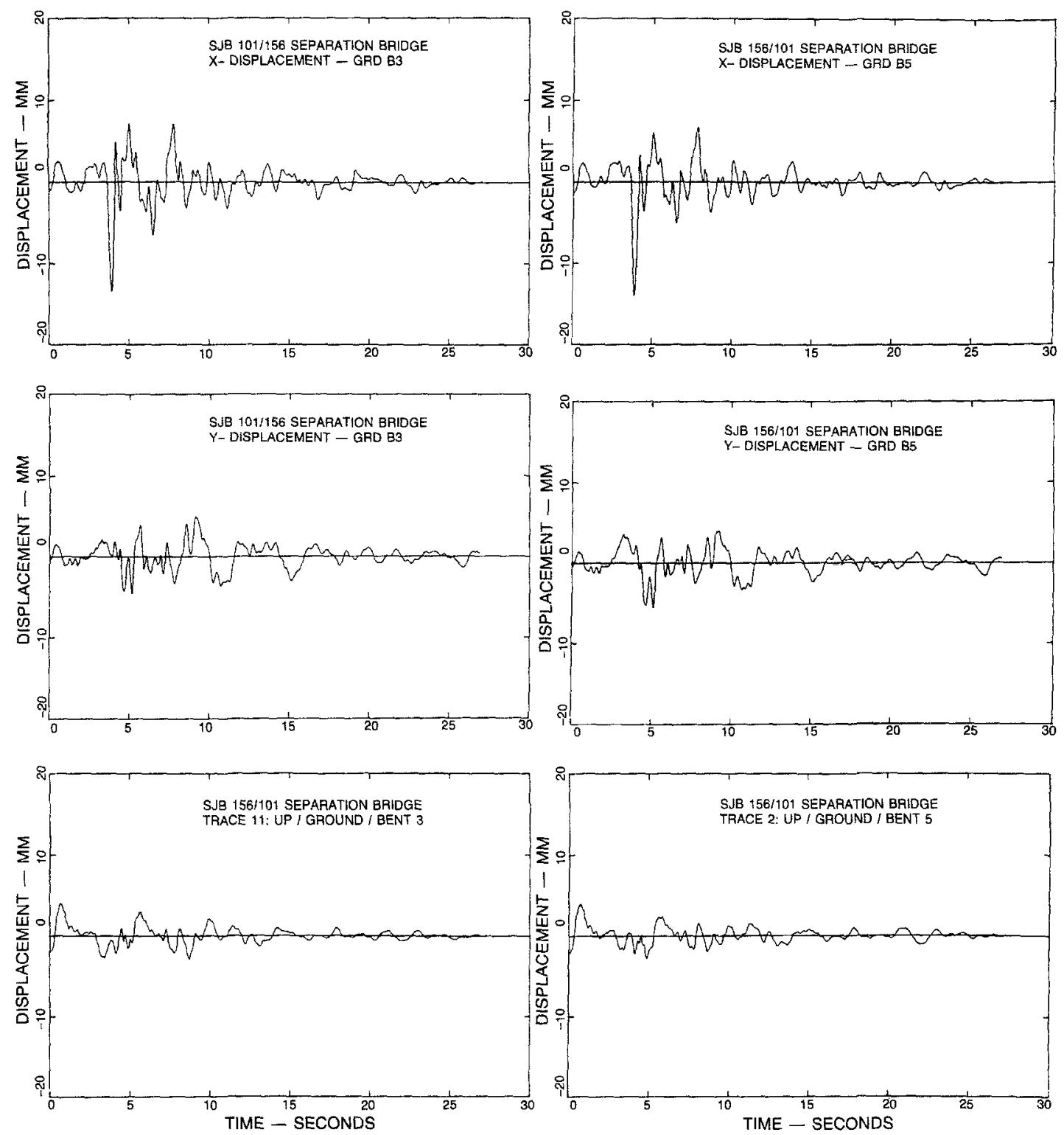

FIG. 4. Ground displacements at bent 3 (left) and bent 5 (right), oriented in the $X$ (top), $Y$ (middle), and $Z$ (bottom) directions shown on Figure 2.

Choosing B3 as a reference $\left(x_{3}=0\right)$ then

$$
\begin{aligned}
& \Delta y(t)=y_{5}(t)-y_{3}(t) \\
& \Delta y(t)=A \cos \omega t \cos \frac{\omega \Delta x}{c}+A \sin \omega t \sin \frac{\omega \Delta x}{c}-A \cos \omega t
\end{aligned}
$$

where $\Delta x$ is the station separation distance projected along the radial direction of wave travel. 

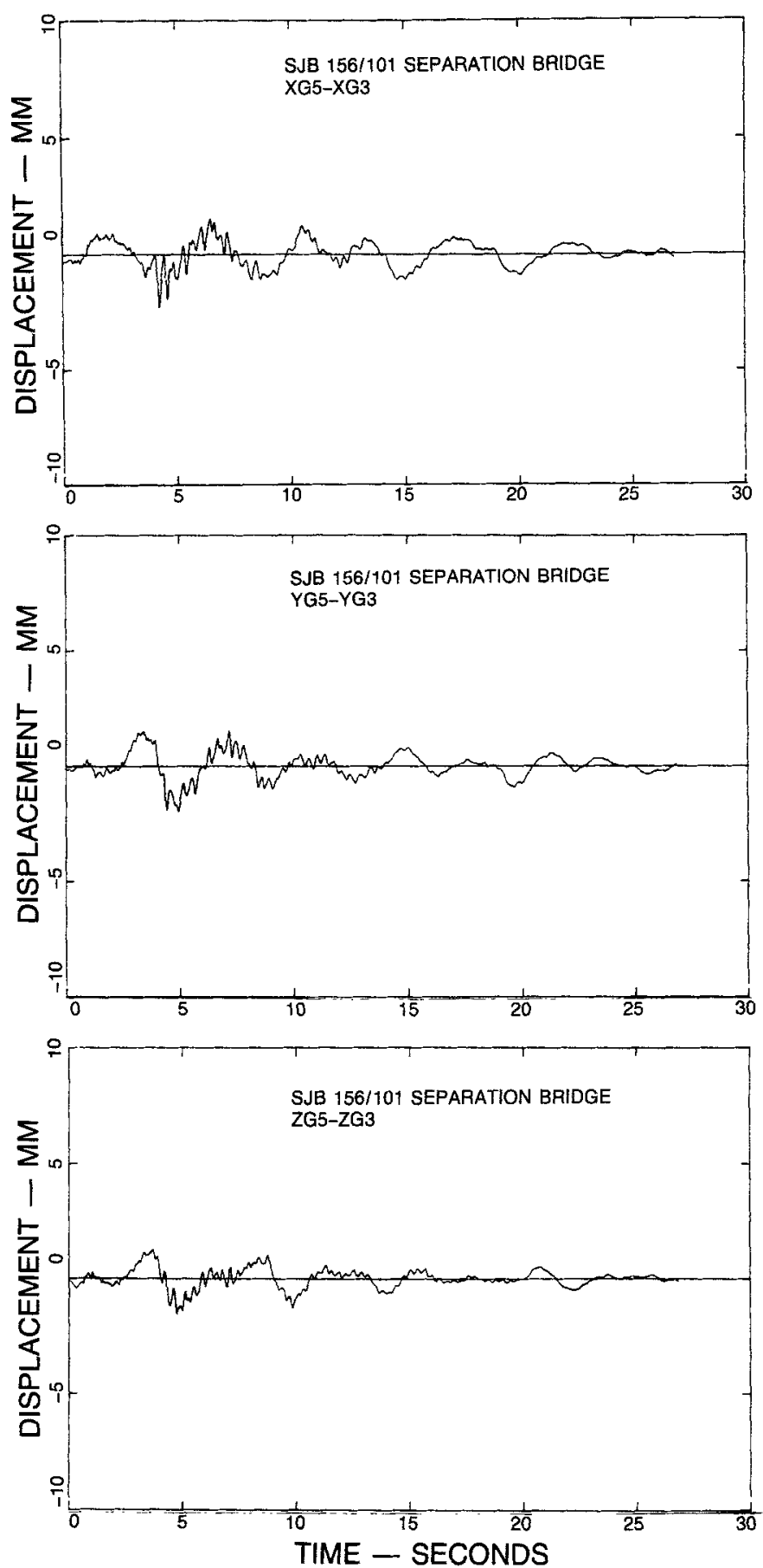

FIG. 5. Relative ground displacements between bents 3 and 5 in $X($ top), $Y$ (middle), and $Z$ (bottom) directions. The ground displacement at bent 3 is taken as the reference.

For low frequencies and closely spaced stations, $\omega \Delta x / c \ll 1$; hence, equation (3) reduces to

$$
\Delta y(t) \approx \Delta A \sin \omega t
$$


where

$$
\Delta A=\frac{A \omega \Delta x}{c}
$$

From the displacement records of Figure 4, the 3-sec motion is estimated to have a sustained amplitude of approximately $5 \mathrm{~mm}, \Delta x$ from the site geometry is about $13 \mathrm{~m}$, and a reasonable value for a surface wave velocity in the low-velocity surficial soil layer might be 300 to $400 \mathrm{~m} / \mathrm{sec}$. These values, substituted into equation (5), give $\Delta A \approx 0.3$ to $0.5 \mathrm{~mm}$. The estimated value for $\Delta A$ from this simplified analysis is a factor of two to four less than seen in Figure 5 , but it does suggest further examination. The observation of surface waves at approximately 3 -sec period in a low-velocity $(c \approx 300 \mathrm{~m} / \mathrm{sec})$ surface layer has been noted by Okamoto $(1973, \mathrm{p}$. 509 ) in data obtained from a linear array of instruments in Japan. In the case of the San Juan Bautista bridge however, such differences in amplitudes are, unfortunately, of the same order as the amplitudes expected from the random digitization noise. If the recording stations had been placed at the abutments, the estimated difference in amplitudes would have been on the order of 1 to $1.5 \mathrm{~mm}$. Furthermore, a more favorable orientation of the bridge with respect to the epicenter would have increased the time delay of signals propagating from one station to the next, thereby creating a more discernible phase shift.

Some stronger evidence that the 3 -sec component is, in part, due to differential support motion is seen by examining the response of the bridge superstructure. The relative horizontal displacements of the top of bent 5 with respect to the base of bent 5 are shown in Figure 6. In each of the $X$ and $Y$ directions, it is apparent that there exists a 3 -sec component with a maximum amplitude of 2 to $3 \mathrm{~mm}$. The nature of the differential motion on the superstructure is very similar to that of the bases of the two bents. This similarity is consistent with differential motion of the supports as well as systematic errors in data processing, but it is not expected from random errors in data processing. The 3 -sec components, if present in the structural response as a result of differential motion occurring along the line of supports, is viewed by the bridge as a pseudostatic component of the excitation since the natural periods of bridge response are much shorter than three seconds (Wilson, 1984).

\section{RAYLEIGH WaVES}

The observations and descriptions of long-period superstructure displacements point to an interesting phenomenon which is not generally present in strong-motion records from buildings. Assuming long-period processing errors are not large, components of ground motion at periods significantly longer than the fundamental period of the structure would appear identically in all accelerograms for a given direction in a building owing to the fact that all floor levels respond identically to a pseudostatic base motion. For a multiple-span bridge, the problem is different since phase delays may occur between supports, and thus components of differential ground motion may have a noticeable effect on the structural response. It is, therefore, of considerable interest for seismic bridge response to explore the nature of the long-period components of differential ground motion in greater detail.

The long-period component having a period of about $3 \mathrm{sec}$ appears to be correlated in the displacement time histories of both ground motions and bridge superstructure responses at B5, as can be seen by comparing Figure 7 and Figure 4 . Since the body- 

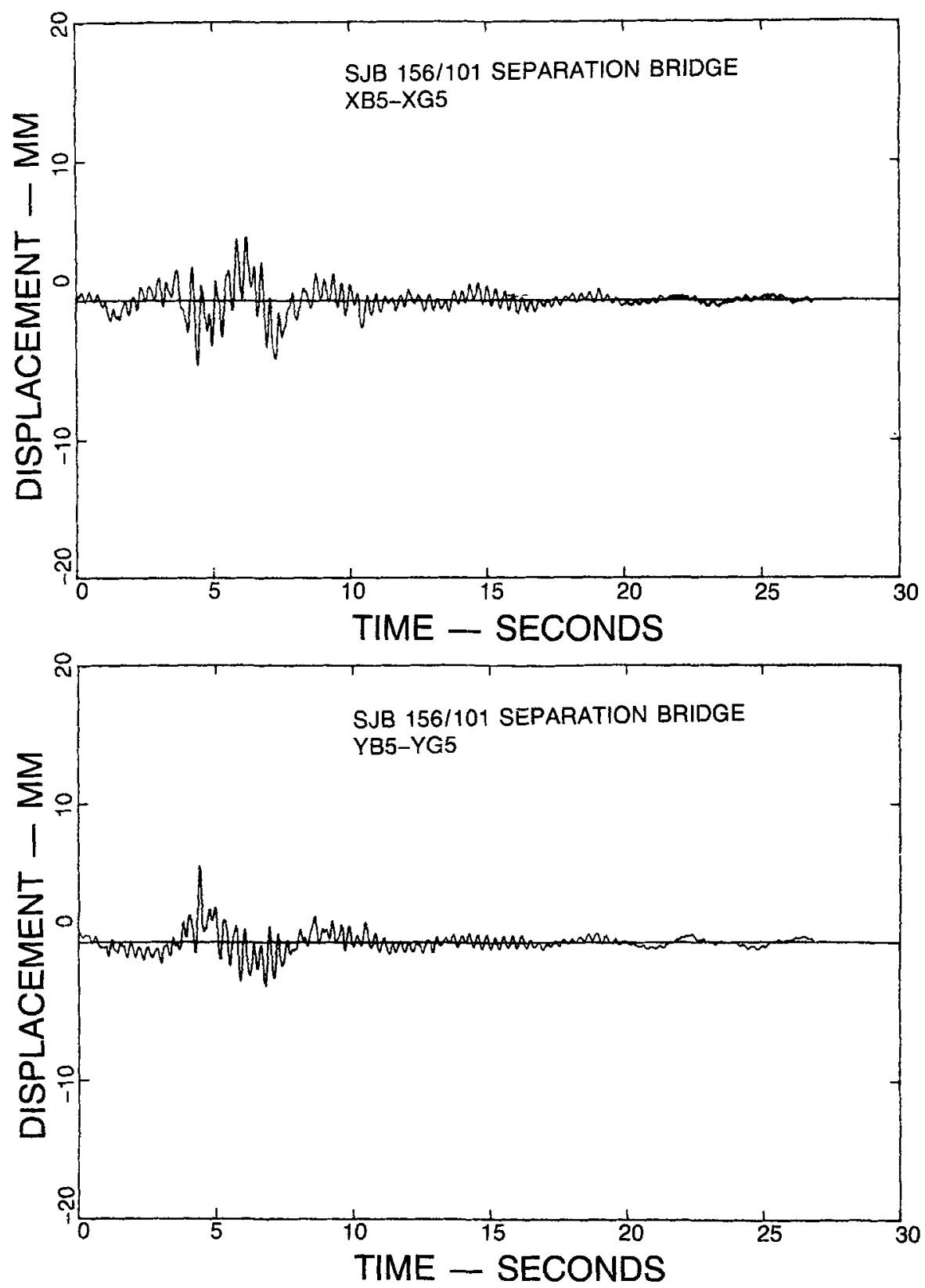

FIG. 6. Relative displacement of the bridge superstructure at the top of bent 5 with respect to the ground at bent 5 in the $X$ (upper) and $Y$ (lower) directions.

wave phases ( $P$ and $S$ waves) are clearly evident on the ground motion accelerograms at relatively high frequencies, it was conjectured that the long-period components observed in the displacements might be due to lower frequency surface waves propagating across the bridge site. The presence of surface waves in recorded strong ground motions has been investigated by several researchers (Anderson, 1974; Hanks, 1975; Liu and Heaton, 1983) who report that a substantial contribution to amplitudes of ground motion can be made by surface waves. 

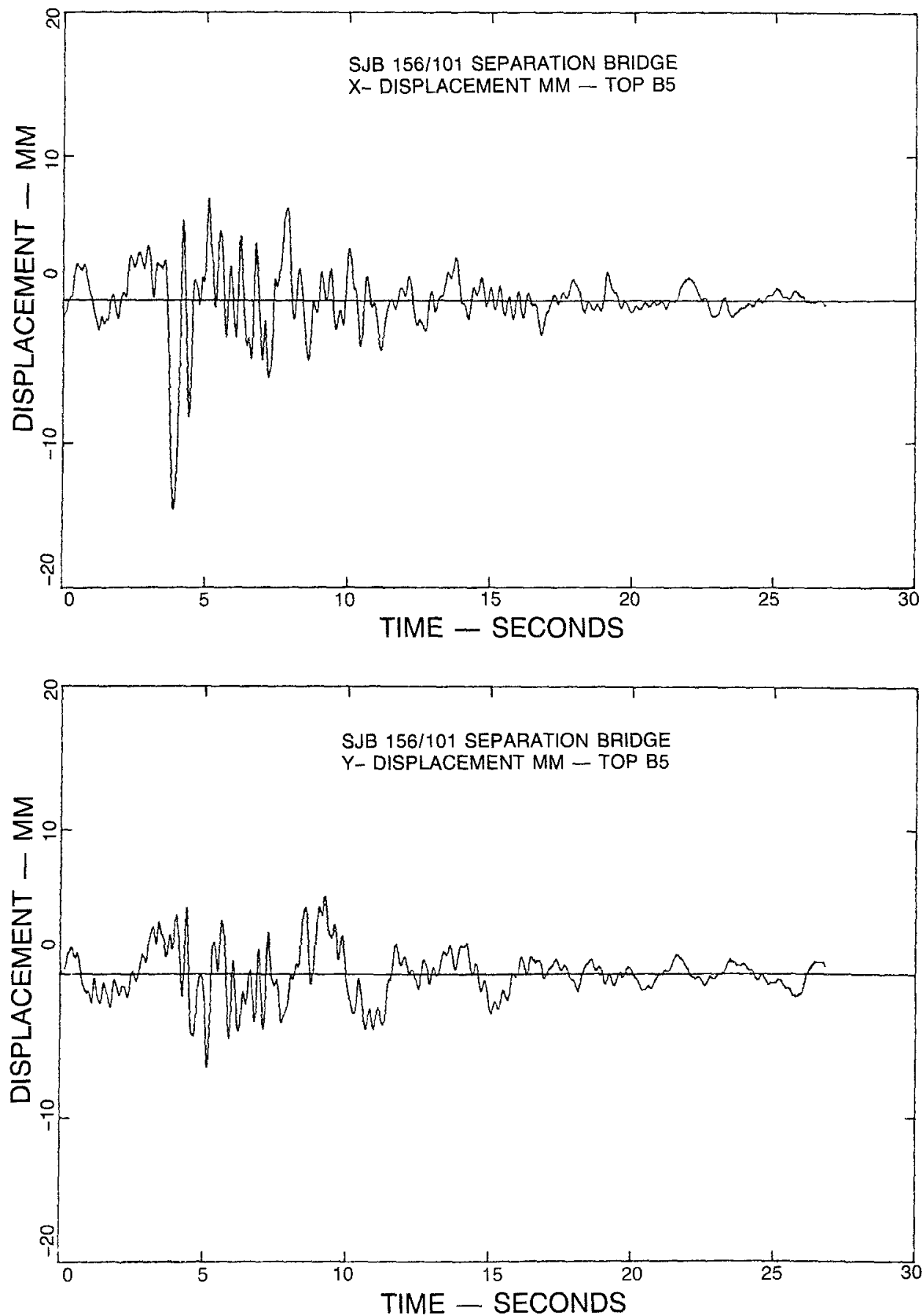

Fig. 7. Absolute displacements of the bridge superstructure at the top of bent 5 in the $X$ and $Y$ directions.

To investigate the presence of surface waves at the San Juan Bautista bridge site, the horizontal components of ground motion recorded at B5 were rotated into radial and transverse components defined relative to the epicenter BK, on Figure 1. These components, as well as the vertical component, are shown in Figure 8. A long- 

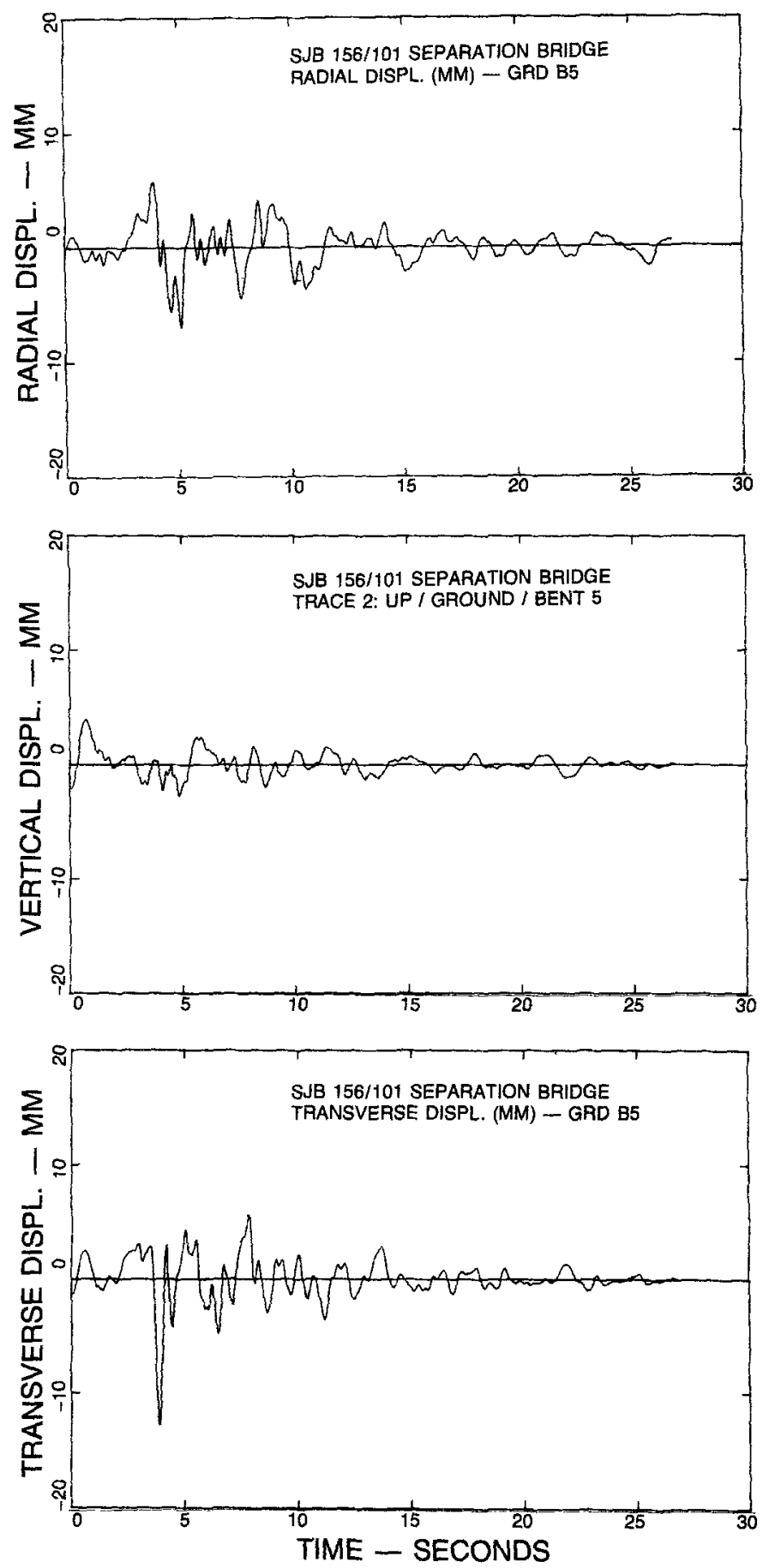

FIG. 8. Radial, vertical, and transverse ground displacements at bent 5 , oriented with respect to the BK epicenter.

period-3-sec component is visible in the radial direction, particularly in the time interval between 4 and $12 \mathrm{sec}$. In the transverse direction, it is more difficult to assess the contributions from long-period components. The fact that the radial direction is near a maxima of Rayleigh wave radiation for the Coyote Lake earth- 
quake (as determined from the focal mechanism published by Liu and Hemberger, 1983) and also the fact that the 3 -sec motion is primarily confined to the radialvertical plane are strong indications that the 3 -sec period disturbance is mainly due to a Rayleigh wave.

In Figure 9, the vertical ground displacements are plotted as a function of the radial displacements for the station at B5, with time as a parameter. For clarity, the plots are shown in 4-sec segments, except for the last plot which is a 6-sec segment. To produce these plots, the radial and vertical displacements shown in Figure 8 were low-pass filtered to remove all frequency components above $1.25 \mathrm{~Hz}$. This was necessary so that higher frequency displacements, resulting from other sources, would not confuse the trace of the long-period motion. The direction of
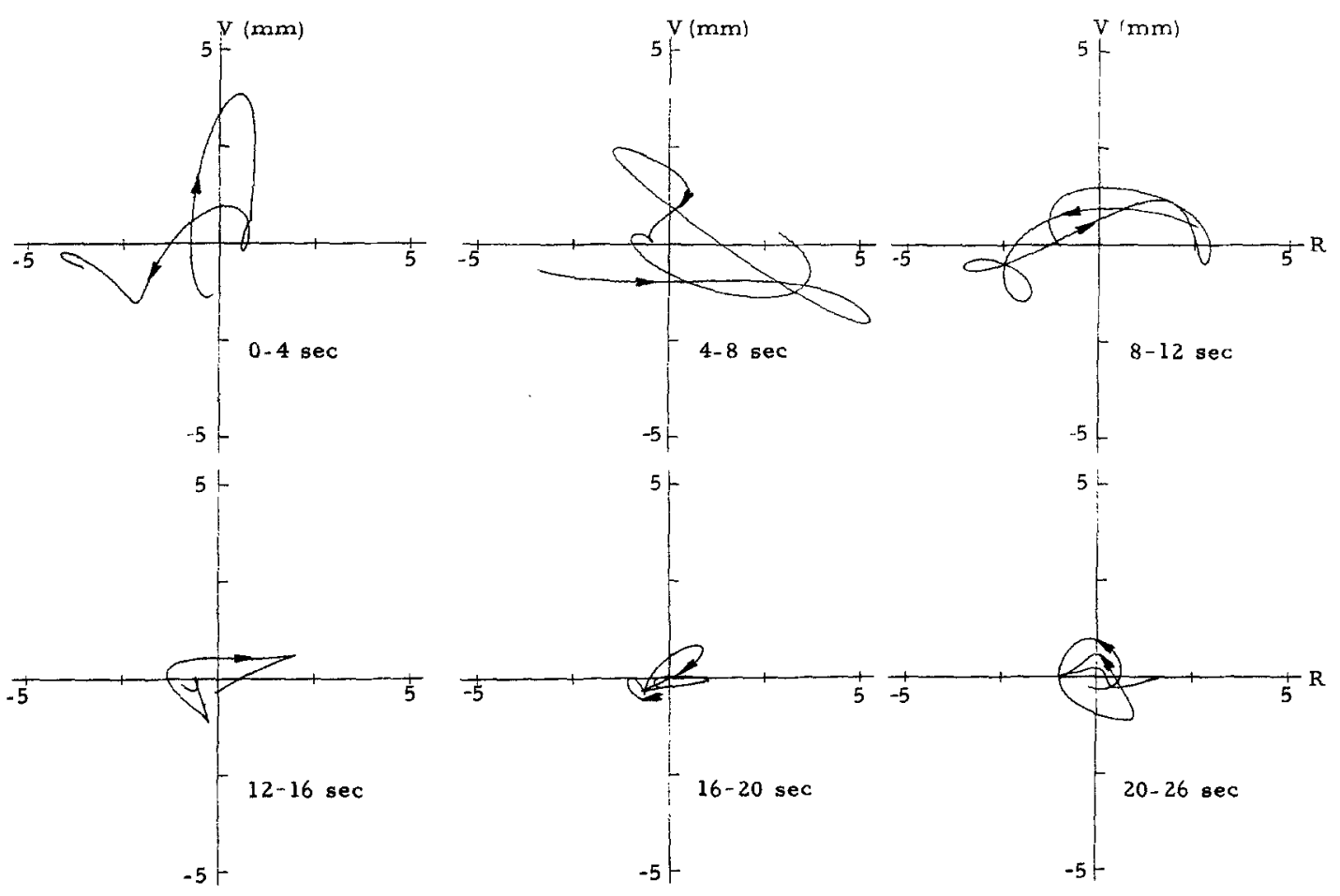

FIG. 9. Particle motions of ground displacements at bent 5. The arrowheads indicate the sense of the particle motions with time as a parameter. $V=$ vertical, $R=$ radial; all axes are scaled in millimeters.

increasing time, and hence the particle motion trajectory, is indicated with arrows on each plot. To a large extent, the particle motions are retrograde within the time interval of 6 to $26 \mathrm{sec}$ ( $26 \mathrm{sec}$ is nearly the end of record), the exception being an interval between 14 and $18 \mathrm{sec}$ when the motion is prograde.

The motion is not always in a well-defined elliptical path, but this is likely attributable to the fact that at an epicentral distance of approximately $30 \mathrm{~km}$, the Rayleigh waves are not yet fully developed. In a study of San Fernando data, Liu and Heaton (1984), found that surface waves started to develop rapidly at epicentral distances of approximately $30 \mathrm{~km}$ and dominated records from stations beyond 40 $\mathrm{km}$, so it seems reasonable to view the San Juan Bautista bridge site as being in a transition zone where rapidly developing surface waves are beginning to emerge. 
Cycles of well-developed retrograde elliptical motions at the B5 station are very clear in Figure 9 in the time intervals of 6 to $10 \mathrm{sec}$ and 18 to $24 \mathrm{sec}$. The elongation of trajectories in the radial direction is caused by surface layers which have a low wave velocity relative to the wave velocity of layers beneath. This elongation phenomenon was also found by Hanks (1975) for Rayleigh waves from the San Fernando earthquake.

The radial polarization of the 3 -sec wave, the delayed onset of retrograde particle motion, and the radial elongation of elliptical particle trajectories all provide evidence to indicate that the 3 -sec wave component is a Rayleigh wave. This evidence is further supported by the location of the bridge near a maxima of the Rayleigh wave radiation pattern for the Coyote Lake earthquake. With the preponderance of the evidence indicating that the 3 -sec component in the displacement is actual ground motion rather than random noise, it seems realistic to expect its appearance in the differential support motions and in the structural deflections of the bridge as well.

\section{Correlation of Vertical Ground accelerations}

The seismic waves first arriving at a site are the $P$ waves, often arriving at a nearly vertical angle of incidence to the ground surface if the source is not too close. The first few seconds of motion at a site are generally composed of simpler waveforms than later arriving signals since refraction, reflection, and modal conversions, although they occur, are not yet complicated by the contributions of $S$ waves and other phases from the source. It is conjectured, therefore, that the vertical motion between the time of the first $P$-wave arrival and the first $S$-wave arrival provides one of the better segments of record to use in a correlation analysis to determine whether any observable differences in accelerations at the two points could be attributed to coherently propagating seismic waves.

The cross-correlation between two time signals $x(t), y(t)$ is given by

$$
\rho_{x y}(\tau)=\frac{R_{x y}(\tau)}{\sqrt{R_{x x}(0) R_{y y}(0)}}
$$

where

$$
\begin{aligned}
& R_{x y}(\tau)=\frac{1}{N-r} \sum_{i=1}^{N-r} x\left(t_{i}\right) y\left(t_{i+r}\right) \\
& R_{x x}(0)=\frac{1}{N} \sum_{i=1}^{N} x^{2}\left(t_{i}\right) \\
& R_{y y}(0)=\frac{1}{N} \sum_{i=1}^{N} y^{2}\left(t_{i}\right)
\end{aligned}
$$

and $\tau=r \Delta t ; r=0,1, \cdots, m$. Using the first 4 sec of vertical accelerations (before the arrival of $S$ waves from the source) at B3 and B5, digitized at 100 points/sec, cross-correlation coefficients (normalized cross-covariances) were computed via equation (6) for various time shifts, $\tau$, between the two records. The record at B5 was taken as a reference, and the record at B3 was shifted by $\pm \tau$ with respect to B5. A similar type of analysis has been used by Smith et al. (1982) in examining data from an array of strong-motion accelerographs near El Centro, California. 
The resulting cross-correlation coefficient $\rho_{x y}(\tau)$, plotted in Figure 10, shows that the time shift which maximizes $\rho_{x y}(\tau)$ is near $0.007 \mathrm{sec}$. This means the maximum correlation between the first 4 sec of vertical excitation occurs when the record of B3 (channel 11 on Figure 2) leads the record of B5 (channel 2) by approximately $0.007 \mathrm{sec}$. This indicates that what is predominantly a seismic $P$ wave propagating from the earthquake source reaches B3 slightly before it reaches B5, an observation that is consistent with the orientation of the bridge with respect to the epicenter.

An approximation to the apparent $P$-wave velocity at the bridge site (the wave transit velocity across the site) can be made using the time delay found above and calculating the additional distance the $P$ wave must travel to reach $\mathrm{B} 5$ along an azimuthal angle of approach from the epicenter of about $12^{\circ}$. This yields an apparent $P$-wave velocity at the bridge site of $1800 \mathrm{~m} / \mathrm{sec}$. This value, however, does not provide a complete picture of the $P$-wave arrivals at the bridge because the first

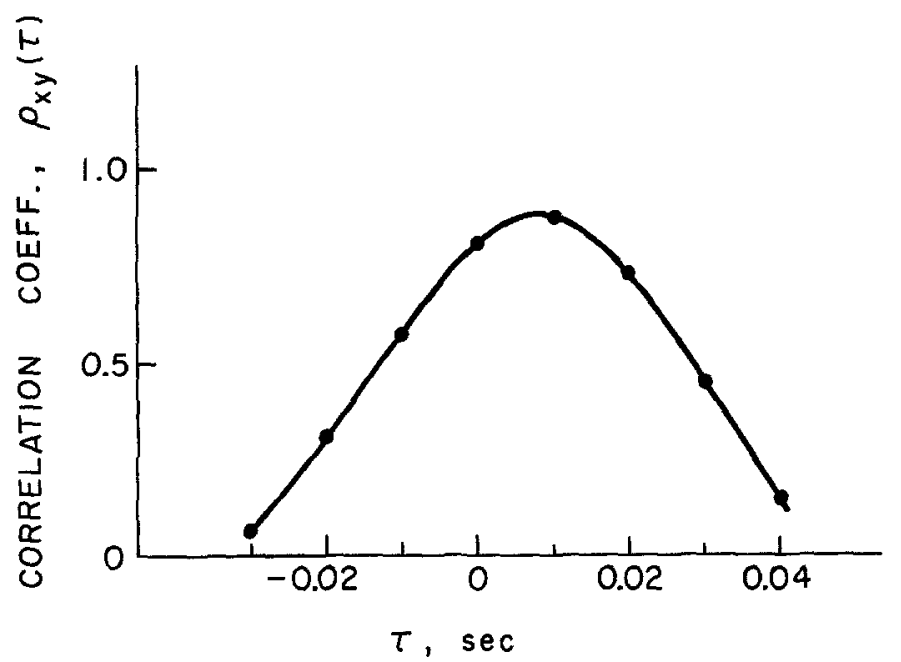

FIg. 10. Cross-correlation of the first $4 \mathrm{sec}$ of vertical $P$-wave motion at bents 3 and 5 . A positive time lag $\tau$ indicates a later wave arrival at bent 5 .

arrivals of $P$ waves are those which travel through the deeper, higher velocity layers and then propagate upwards to the surface. If the angle of incidence of $P$ waves at the surface were zero, i.e., the direction of propagation were vertical, all support points of the bridge would be subjected to in-phase (correlated) motions. However, this is not the case for the San Juan Bautista bridge. The time lag between $P$-wave arrivals at B3 and B5 indicates that the $P$ waves are arriving at an oblique angle of incidence to the ground surface, thereby subjecting the bridge to a source of multiplesupport excitation in addition to that due to the long-period surface waves discussed previously.

An estimate of the angle of incidence can be made by using the time lag of approximately $0.007 \mathrm{sec}$ computed from the correlation analysis, and a reasonable value for the $P$-wave velocity of the soil in the vicnity of the footings. From reported geotechnical investigations of the site soil conditions, a shear wave velocity of 460 $\mathrm{m} / \mathrm{sec}$ is considered to be appropriate for the bridge's foundation soil. Using relations for the propagation of a planar wave in a homogeneous elastic medium, the 
corresponding $P$-wave velocity is approximately $800 \mathrm{~m} / \mathrm{sec}$. The angle of wave emergence with respect to the ground surface $\theta$, shown in Figure 11, can then be found using

$$
\alpha_{a}=\frac{\alpha}{\cos \theta} .
$$

Equation (10) expresses the relationship between the $P$-wave velocity in the foundation soil $\alpha$, and the apparent $P$-wave velocity across the ground surface, $\alpha_{a}$, as a function of the angle of wave emergence. Using $\alpha=800 \mathrm{~m} / \mathrm{sec}$ and $\alpha_{a}=1800 \mathrm{~m} /$ sec, the angle of wave emergence is found to be $64^{\circ}$. (The angle of incidence is, therefore, $90^{\circ}-64^{\circ}=26^{\circ}$.)

An estimate of the phase difference between motions occurring at the two abutments due to the traveling $P$ wave may be made using the predominant

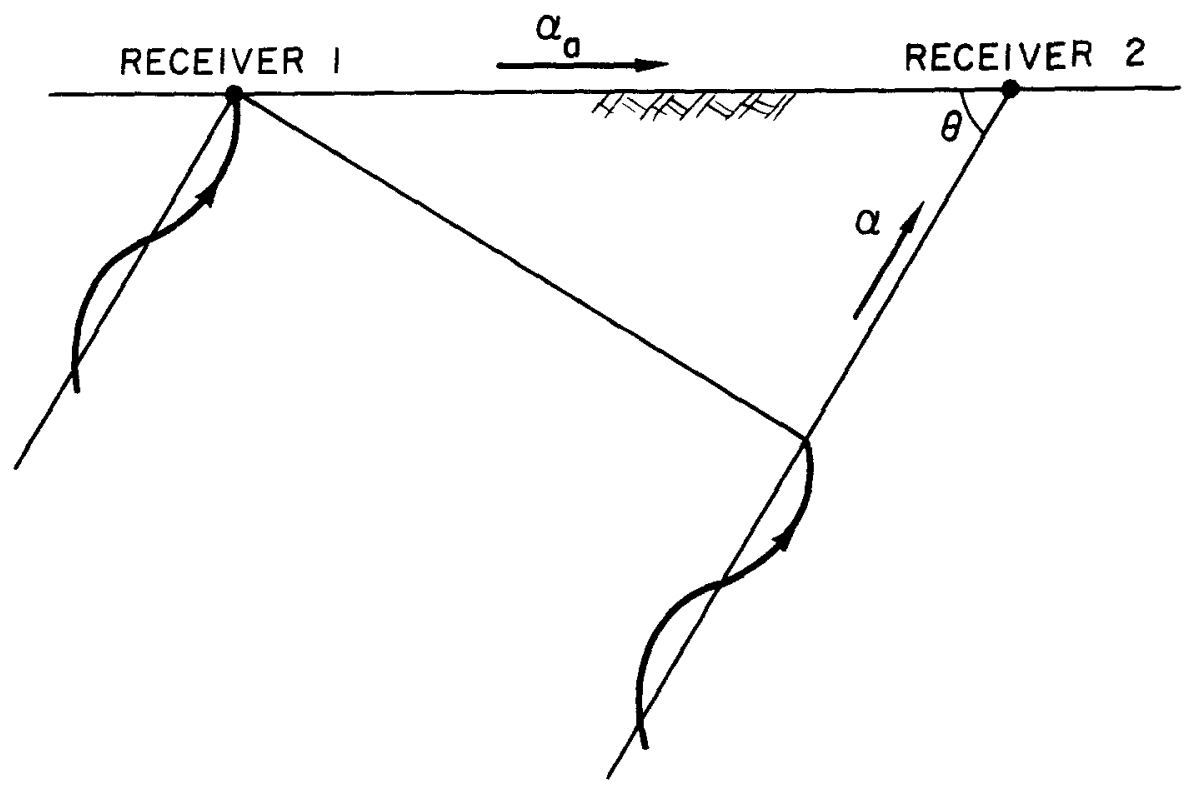

FIG. 11. True $(\alpha)$ and apparent $\left(\alpha_{a}\right)$ seismic wave velocities for an angle of emergence $\theta$.

frequency $f_{p}$, of the $P$ wave and relating this to the $P$ wavelength $\lambda_{p}$, via $\lambda_{p}=\alpha / f_{p}$. From an examination of the first $4 \mathrm{sec}$ of the vertical acceleration records at B3 and $\mathrm{B} 5$, the predominant $P$-wave frequency was estimated to be about $9 \mathrm{~Hz}$. Using the surface layer $P$-wave velocity of $800 \mathrm{~m} / \mathrm{sec}$ gives a $P$ wavelength near the surface of approximately $89 \mathrm{~m}$. If it is assumed that the delay of $0.007 \mathrm{sec}$ between B3 and B5 can be extended uniformly over the length of the bridge, then the $P$ wave will arrive at A7 $0.021 \mathrm{sec}$ after its arrival at A1. Thus, the maximum anticipated phase difference between abutments due to the first few seconds of observed nonvertically incident $P$ waves is approximately $0.38 \pi$, or about $68^{\circ}$.

A study of the Fourier spectra of vertical motions indicates that $9 \mathrm{~Hz}$ is about the maximum frequency component which has a significant contribution to ground motions. Lower frequency $P$ waves will have longer wavelengths, which will result in smaller phase differences between abutments than the previously estimated $68^{\circ}$. 
This gives an indication that differential support motion of the San Juan Bautista bridge due to traveling $P$ waves is likely to be minimal for the 1979 Coyote Lake event.

\section{CONCLUSIONS}

The presence of long-period components in the ground displacement records at the San Juan Bautista bridge site may be the result of one or more of the following sources: long-period seismic waves; systematic data processing errors; and random data processing errors. While systematic data processing errors cannot be completely ruled out by the authors, several lines of evidence suggest that the $3 \mathrm{sec}$ component observed in the ground displacement records is caused by a Rayleigh wave traveling across the bridge site. Radial polarization of the $3 \mathrm{sec}$ component, retrograde elliptical particle motions, and the location of the bridge near a maxima of the Rayleigh wave radiation pattern of the Coyote Lake earthquake, indicate the likely presence of a Rayleigh surface wave at the bridge site.

Although random digitization noise might be of the same general amplitude as the observed displacements, the fact that the 3 -second displacement components are correlated at the two ground sites and in the superstructure records, seems to rule out the presence of any significant amount of random processing errors at a 3 second period.

In the vertical direction, a very small time delay was detected between the arrival of $P$ waves at bent 3 and bent 5 . At least in this case, the influence of differential support motion induced by high-frequency body waves in the vertical direction appears to be much less noticeable than the differential motion induced by longperiod surface waves.

Since the periods of all the structural modes of the San Juan Bautista bridge are much shorter than the 3-sec surface wave period, the response of the bridge to these waves was essentially static. The results of this research confirm that, for engineering purposes, effects of differential support motion could normally be neglected in computing the earthquake response of moderately stiff, medium length highway bridges founded on uniform soil conditions. The more common assumption of rigid base excitation seems sufficient for such structures. For long span or tall bridge structures, when the fundamental frequency may be close to the frequency of large amplitude surface waves, long-period differential support motions may significantly influence the dynamic response of the bridge. Since strong-motion accelerograms are the basic source of data for earthquake engineering research, it is important that highway bridges in seismic regions continue to be instrumented, especially to include a sufficient deployment of instruments on long span bridges so that both spatial and temporal variations in support motions can be evaluated.

\section{ACKNOWLEDGMENTS}

The authors would like to thank John Ragsdale, formerly of the California Division of Mines and Geology, for his assistance in obtaining the accelerogram records used in this study. Also, our thanks to Jim Gates of the California Department of Transportation for his help throughout the project.

This research was partially supported by Grant CEE81-19962 from the National Science Foundation. J. C. W. would also like to acknowledge the support of the Natural Sciences and Engineering Research Council of Canada while at the California Institute of Technology.

\section{REFERENCES}

Abdel-Ghaffar, A. M. (1977). Studies on the effect of differential motions of two foundations upon the response of the superstructure of a bridge, Earthquake Engineering Research Laboratory, EERL 77 02, California Institute of Technology, Pasadena, California. 
Anderson, J. (1974). A dislocation model for the Parkfield earthquake, Bull. Seism. Soc. Am. 64, 671686.

Basili, M. and G. Brady (1978). Low frequency filtering and the selection of limits for accelerogram corrections, Proceedings of the 6th European Conference on Earthquake Engineering.

Bogdanoff, J. L., J. E. Goldberg, and A. J. Schiff (1965). The effect of ground transmission time on the response of long structures, Bull. Seism. Soc. Am. 55, 627-640.

Fletcher, J. B., A. G. Brady, and T. C. Hanks (1980). Strong-motion accelerograms of the Oroville, California, aftershocks: data processing and the aftershock of 0350 August 6, 1975, Bull. Seism. Soc. Am. 70, 243-267.

Hanks, T. C. (1975). Strong ground motion of the San Fernando, California, earthquake: ground displacements, Bull. Seism. Soc. Am. 65, 193-225.

Hudson, D. E. (1979). Reading and interpreting strong motion accelerograms, Earthquake Engineering Research Institute, Berkeley, California.

Joyner, W. B., R. E. Warrick, and T. E. Fumal (1981). The effect of Quaternary alluvium on strong ground motion in the Coyote Lake, California, earthquake of 1979, Bull. Seism. Soc. Am. 71, 13331349.

Liu, H.-L., and D. V. Helmberger (1983). The near-source ground motion of the 6 August 1979 Coyote Lake, California, earthquake, Bull. Seism. Soc. Am. 73, 201-218.

Liu, H.L. and T. Heaton (1984). Array analysis of the ground velocities and accelerations from the 1971 San Fernando, California earthquake, Bull. Seism. Soc. Am. 74, 1951-1968.

Okamoto, S. (1973). Introduction to Earthquake Engineering, John Wiley and Sons, Inc., New York.

Porcella, R. L., R. B. Matthiesen, R. D. McJunkin, and J. T. Ragsdale (1979). Compilation of strongmotion records recovered from the Coyote Lake earthquake of 6 August 1979, California Division of Mines and Geology Preliminary Report 25, and U.S. Geol. Surv., Open-File Rept. 79-385.

Porter, L. D., A. G. Brady, P. N. Mork, and V. Perez (1983). Processed data from the San Juan Bautista 101/156 Separation Bridge and the San Juan Bautista Freefield Records, Coyote Lake Earthquake, 6 August 1979, U.S. Geol. Surv., Special Publication 64.

Scott, R. F. (1981). Foundation Analysis, Prentice-Hall, Inc., Englewood Cliffs, New Jersey.

Smith, S. W., J. E. Ehrenberg, and E. N. Hernandez (1982). Analysis of the El Centro differential array for the 1979 Imperial Valley earthquake, Bull. Seism. Soc. Am. 72, 237-258.

Trifunac, M. D., F. E. Udwadia, and A. G. Brady (1973). Analysis of errors in digitized strong-motion accelerograms, Bull. Seism. Soc. Am. 63, 157-187.

Uhrhammer, R, (1980). Observations of the Coyote Lake, California, earthquake sequence of August 6, 1979, Bull. Seism. Soc. Am. 70, 559-570.

Werner, S. D. and L. C. Lee (1980). The three-dimensional response of a bridge structure subjected to traveling Rayleigh waves, $S V$-waves and $P$-waves, Agbabian Associates, EI Segundo, California.

Werner, S. D., Lee, L. C., Wong, H. L., and M. D. Trifunac (1977). An evaluation of the effects of traveling seismic waves on the three-dimensional response of structures, Agbabian Associates, El Segundo, California.

Wilson, J. C. (1984). Analysis of the observed earthquake response of a multiple span bridge, Earthquake Engineering Research Laboratory, EERL 84-01, California Institute of Technology, Pasadena, California.

Earthquake EngineERING Research Laboratory

CALIFORNIA INSTITUTE OF TECHNOLOGY

Pasadena, California 91125

Manuscript received 15 March 1985 